\title{
POSITIVE SOLUTIONS OF SECOND ORDER MULTI-POINT BOUNDARY VALUE PROBLEMS WITH NON-HOMOGENEOUS BOUNDARY CONDITIONS
}

\author{
JAMES S. W. WONG
}

Abstract. We are interested in the existence of positive solutions to multi-point boundary value problems for second order nonlinear differential equations with non-homogeneous boundary conditions. We show that results for the multi-point problems can be proved much in a similar way by methods available for the three point problem.

Mathematics subject classification (2010): 34B10, 34B15.

Keywords and phrases: boundary value problems, second order, multi-point, non-homogeneous boundary conditions.

\section{REFERENCES}

[1] C. Bandle, C. V. Coffman And M. Marcus, Nonlinear elliptic problems in annular domains, J. Diff. Equ., 69 (1987), 322-345.

[2] J. R. CAnnon, The One-dimensional heat equation, Encyclopedia of Mathematics and Its Applications, vol. 23, Addison-Wesley, Menlo Park, California, USA, 1984.

[3] J. R. CAnnon, E. P. Esteva And J. VAn DeR Hock, A Galerkin procedure for the diffusion equation subject to specification of mass, SIAM J. Numer. Anal., 24 (1987), 499-515.

[4] K. Deimling, Nonlinear Functional Analysis, Springer, Berlin, 1985.

[5] P. W. Eloe AND J. Henderson, Multipoint boundary value problems of ordinary differential equations, J. Diff. Equ., 114 (1994), 232-242.

[6] P. W. Eloe AND B. AhMAD, Positive solutions of a nonlinear nth order boundary value problem with non local conditions, Appl. Math. Lett., 18 (2005), 521-527.

[7] L. ERBE, Eigenvalue criteria for existence of positive solutions to nonlinear boundary value problems, Math. Comput. Model, 32 (2000), 529-539.

[8] L. ERBE AND H. WANG, On the existence of positive solutions of ordinary differential equations, Proc. Amer. Math. Soc., 120 (1994), 743-748.

[9] J. R. L. GRAef AND L. Kong, Solutions of second order multi-point boundary value problems, Math. Proc. Camb. Phil. Soc., 145 (2008), 489-510.

[10] J. R. GRAEF, L. Kong AND Q. Kong, Higher order multi-point boundary value problems, Math. Nachr., 2009 (to appear).

[11] D. Guo and V. Lakshmikantham, Nonlinear Problems on Abstract Cones, Academic Press, Orlando, 1988.

[12] Y. GUO, W. SHAN AND W. GE, Positive solutions for second order m-point boundary value problems, J. Comput. Appl. Math., 151 (2003), 415-424.

[13] Y. GUO AND J. TIAN, Positive solutions of m-point boundary value problems for higher order ordinary differential equations, Nonlinear Analysis, 66 (2007), 1573-1586.

[14] C. P. GUPTA, Solvability of a three-point nonlinear boundary value problem for a second order ordinary differential equations, J. Math. Anal. Appl., 168 (1992), 540-551.

[15] C. P. GuPTA, A note on a second order three-point boundary value problem, J. Math Anal. Appl., 186 (1994), 277-281.

[16] C. P. GUPTA, A sharper condition for solvability of a three-point nonlinear boundary value problem, J. Math. Anal. Appl., 205 (1997), 586-597. 
[17] C. P. GUPTA AND B. TROFIMChUK, Existence of a solution to a three-point boundary value problem and the spectral radius of a related linear operator, Nonlinear Analysis TMA, 34 (1998), 489-507.

[18] D. D. HAI, Positive solutions for semi-linear elliptic equations in annualar domains, Nonlinear Analysis TMA, 37 (1999), 1051-1058.

[19] H. HAN, Positive solutions for a three-point boundary value problem, Nonlinear Analysis, 66 (2007), 679-688.

[20] V. A. IL'IN AND E. I. MoISEEv, Nonlocal boundary value problem of the first kind for a SturmLiouville operator in its differential and finite difference aspects, Diff. Eq., 23 (1987), 803-810.

[21] V. A. IL'IN AND E. I. MoISEev, Nonlocal boundary value problem of the first kind for a SturmLiouville operator, Diff. Eq., 23 (1987), 979-987.

[22] N. I. IONKIN, The solution of a certain boundary value problem of the theory of heat conduction with a nonclassical boundary condition, Diff. Uravn., 13 (1977), 294-304.

[23] N. I. KAMYUIN, A boundary value problem in the theory of the heat conduction with nonclassical boundary condition, USSR Comput. Math. Phy., 4 (1964), 33-59.

[24] L. KONG AND Q. Kong, Multi-point boundary value problems of second order differential equations, Nonlinear Analysis, 58 (2004), 909-931.

[25] L. Kong AND Q. Kong, Multi-point boundary value problems of second order differential equations II, Comm. Appl. Nonlinear Analy., 4 (2007), 93-111.

[26] L. Kong AND Q. Kong, Higher order multi-point boundary value problems with nonhomogeneous boundary conditions, Nonlinear Analysis, 2009 (to appear)

[27] M. Krein And M. Rutman, Linear Operators leaving invariant a Banach Space, Uspehi Mat. Nauk., 3 (1948), 3-95 (Amer. Math. Soc. Trans., 10 (1962), 199-325).

[28] M. A. KRanosels KiI, Positive solutions of Operator Equation, Noordhoff, Groningen, 1964.

[29] M. K. KWONG AND J. S. W. WONG, The shooting method and nonhomogeneous multi-point BVPs of second-order ODE, Boundary Value Problems, (2007), art. ID64012, 16 pages.

[30] M. G. LEE AND S. S. Lin, On the positive solutions for semilinear elliptic equation on annular domain with nonhomogeneous Dirichlet boundary condition, J. Math. Anal. Appl., 181 (1994), 348361.

[31] B. LiU, Positive solutions of a nonlinear three point boundary value problem, Appl. Math. Comp., 132 (2002), 11-28.

[32] B. LiU, Positive solutions of a nonlinear three-point boundary value problem, Comp. Math. Appl., 44 (2002), 201-211.

[33] X. LIU, Nontrivial solutions of singular nonlinear m-point boundary value problems, J. Math. Anal. Appl., 284 (2003), 576-590.

[34] Y. LiU, Nonhomogeneous boundary value problems of higher order differential equation with pLaplacian, Electronic J. Diff. Equ., 2008, 20 (2008), 1-43.

[35] Y. LIU, Solutions to second order non-homogeneous multi-point BVP's using a fixed point theorem, Electronic J. Diff. Equ., 2008, 96 (2008), 1-52.

[36] R. MA, Positive solutions of a nonlinear three-point boundary value problem, Electronic. J. Diff. Equ., 34 (1999), 1-8.

[37] R. MA, Positive solutions for second order three point boundary value problems, Appl. Math. Letters, 14 (2001), 1-5.

[38] R. MA, Existence of positive solutions for superlinear semi-positone m-point boundary value problems, Proc. Roy. Edinburgh, 46 (2003), 279-292.

[39] R. MA, Multiplicity results for a three-point boundary value problem at reasonance, Nonlinear Analysis, 53 (2003), 777-789.

[40] R. MA AND N. CASTANEDA, Existence of solutions of nonlinear m-point boundary value problems, J. Math. Anal. Appl., 256 (2001), 556-567.

[41] R. MA AND Y. AN, Global structure of positive solutions for nonlocal boundary value problems involving integral conditions, Nonlinear Analysis, 71 (2009), 4364-4376.

[42] M. Moshins Ky, Sobre los problemas de condiciones a la frontier en una dimension de caracteristicas discontinues, Bol. Soc. Mat. Mexicana, 7 (1950), 1-25.

[43] I. RACHUNKOVA, Multiplicity results for four-point boundary value problems, Nonlinear Analysis, 18 (1992), 495-505.

[44] I. Rachunkova, On the existence of two solutions of the four-point problem, J. Math. Anal., 193 (1995), 245-254. 
[45] W. SUn, S. CHEN, Q. ZHANG AND C. WANG, Existence of positive solutions to m-point unhomogeneous boundary value problems, J. Math and Appl., 330 (2007), 612-621.

[46] Y. Sun, Optimal existence criteria for symmetric positive solutions to a three-point boundary value problem, Nonlinear Analysis, 66 (2007), 1051-1063.

[47] S. Timoshenko, Theory of elastic stability, McGraw Hill, New York, 1961.

[48] H. WANG, On the existence of positive solutions for semi-linear elliptic equations in the annulus, J. Diff. Equ., 109 (1994), 1-7.

[49] J. R. L. WeBB, Positive solutions of some three point boundary value problem via fixed point index theory, Nonlinear Anal., 47 (2001), 4319-4332.

[50] J. R. L. WEBB AND K. Q. LAN, Eigenvalue criteria for existence of multiple positive solutions of nonlinear boundary value problem of local and nonlocal type, Top. Methods Nonlinear Anal., 27 (2006), 91-115.

[51] J. R. L. WebB AND G. Infante, Positive solutions of nonlocal boundary value problems involving integral conditions, Nonlinear Differential Equations Appl., 15 (2008), 45-67.

[52] E. ZeIdler, Nonlinear Functional Analysis and Applications, Vol. 1 Fixed Point Theorems, SpringerVerlag, New York 1986.

[53] X. ZhANG AND M. Feng, Positive solutions for a class of second order singular boundary value problems, Nonlinear Analysis, 69 (2008), 1287-1298.

[54] G. Zhang AND J. Sun, Positive solutions of m-point boundary value problems, J. Math. Anal. Appl., 291 (2004), 406-418.

[55] X. Zhang AND Y. SUn, Monotone positive solutions of second order multi-point boundary value problems, Appl. Math. Computation, 207 (2009), 493-500.

[56] Z. ZhANG AND J. WANG, Positive solutions to a second order three-point boundary value problem, J. Math. Anal. Appl., 205 (1997), 586-597 and 285 (2003), 237-249. 